\title{
A Study on Aerodynamic Behavior of Subsonic UAVs' Wing Sections with Flaps
}

\author{
Halil Yalcin Akdeniz ${ }^{1 \star}$ \\ ${ }^{1}$ Eskisehir Osmangazi University, Eskisehir Vocational School, Odunpazar, Eskisehir \\ hyakdeniz26@gmail.com (D) 0000-0003-2101-6151
}

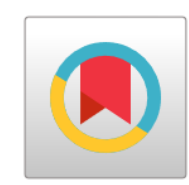

Keywords

\author{
Aerodynamic Performance \\ Wing Design \\ UAVs \\ NACA 4415 \\ XFLR5
}

\section{Time Scale of Article}

Received 5 April 2021 Revised to 16 May 2021 Accepted 30 May 2021 Online date 27 June 2021

\section{Introduction}

Today, most of the budgets or investments made for UAVs are within the scope of military activities. These military activities are mainly in the form of control, surveillance, and intelligence activities. Apart from these, another area of use in the military field is the workgroups such as chemical, biological, nuclear, and radiological activities. Contrary to popular belief, UAVs are not used only in military applications. The UAV industry has developed rapidly, especially with the United States government allowing UAVs in civil aviation besides military fields. The use of UAVs is increasing. Especially in dangerous and risky applications and in areas where human use is inefficient and takes a long time, it is preferred because of the convenience it provides. It can also be preferred frequently in nuclear activities, which is detrimental for the human. Internet services and social media applications used in all areas of life also benefit from UAV technology. It is thought that UAVs in both civilian and military aviation will reach much wider dimensions in the future. It is foreseen to be used for air transportation, air battles, direct target scanning-recognition-destruction, destruction of enemy air defence targets, network node combat contact, electronic attack, defence, or attack against attack. Cost reduction is aimed at the production stage of UAVs. At this point, considering that UAVs also go through similar R\&D processes; All component/system designs, calculations, analyzes, modelling, and simulations appear to be serious financial items for UAVs as well. Because the design-calculation-analysismodelling simulation stages are the first and most important steps of UAV system production. These stages offer opportunities such as making repeatable tests and

*: Corresponding Author Halil Yalcin Akdeniz, hyakdeniz26@gmail.com DOI: 10.23890/IJAST.vm02is01.0103 
system verification. In this way, various studies are carried out to reduce costs. Free software studies have an essential place in these studies. Their quality and functionality vary, as they are generally carried out independently. Free software studies primarily focused on mechanical and aerodynamic parts. Because these two parameters are the areas where the designer has the highest capacity to act. There are many successful studies on this subject. With these studies and created software, costs are reduced, and efficient use of resources is provided (Gupta et al., 2013, Yigit et al., 2013; Vogeltanz, 2016; FAS, 2021a; FAS, 2021b; Quintana, 2008; Nonami et al. 2010).

From the aerodynamic perspective, wings are crucial for any aerial vehicle and other design components. Wings are the building blocks of a suitable aircraft, and airfoils are the core component required to craft a welldesigned wing. Due to their smaller size and velocity, UAVs (Unmanned Air Vehicles) need wings other than typical aircraft. The design of the wings for such aircraft must be carried out with data from previous airfoil studies. An airfoil is a cross-sectional form of an object that produces an aerodynamic force as it is moved through fluid-like air. Airfoils are used as wings for lifting or propeller blades for thrust output on aircraft. Both these forces are produced perpendicular to the airflow. The unit of this force is called lift, which is perpendicular to motion direction. The element is called the drag parallel to the movement direction. Airfoils are based on the main camber and the chord of two different forms. The symmetrical airfoil without a camber produces a lift on either side and also while flying inverted. To prevent the aircraft to swing too far to the right or the connection without any manual input, the airfoils present in stabilizers and rudders must be of a symmetrical design. The other type of airfoil is an asymmetric airfoil with a medium chord camber. These types of airfoils generate uneven lift and are much safer for conventional aircraft than symmetrical airfoils. They are used to produce more lift than symmetrical wings in the wing section of the aircraft. When aircraft are inverted, asymmetric airfoils do not produce lifts. Therefore, for acrobatic aircraft, only symmetrical airfoils are used. These considerations affect the selection of the aircraft type to be used. Preliminary calculations and estimates that are vital for selecting an airfoil have to take place before the design and analysis process is started (Phillips, 2004; Khan, 2019; Joseph, 2020; Akdeniz, 2020).

The earliest significant work started in the late 1800 s on the development of airfoil parts. H.F. Phillips patented a sequence of airfoil types in 1884 . They were tested in one of the earliest wind tunnels in which "artificial currents of air were produced from induction by a steam jet in a wooden trunk or conduit." A large proportion of airfoils have been developed and tested by the National Aeronautics Advisory Committee (NACA). The UIUC Airfoil Coordinates database now offers the modern airfoil database. The designers still have not specified the perfect airfoil. The fact that the flow conditions and the design objectives vary from one application to the next explains the modern airfoils. The subsonic flight designs of airfoil vary from those of supersonic flight. Subsonic flight airfoils have a characteristic shape with a rounded leading edge, followed by a sharp trailing edge, often with a symmetric curvature of upper and lower surfaces (UIUC Aerofoil Coordinates Database, 2020; Joseph, 2020; Alam et al., 2021; Phillips, 2004; Khan, 2019; Akdeniz, 2020).

Even though studies on the aerodynamics of airfoils have been conducted for a long time, driven by the needs of applications, the knowledge obtained thus far is limited due to recent developments such as small wind turbines, rooftop wind turbines, UAV, MAV, and NAV. Because the vehicles mentioned above and systems operate at low Reynolds numbers in the order of 104-106, the effect of turbulence intensity on airfoil aerodynamic performance is significant. At low Reynolds numbers, the presence of turbulence can effectively delay the flow separation caused by the transition and cause significant aerodynamic performance changes. To better understand the ability of turbulence to influence the aerodynamic characteristics of an airfoil, a detailed experimental study is required (Arunvinthan et al., 2019).

Some researchers have investigated the performance behaviour of airfoils as experiment-based or softwarebased. Some of them are given as follows (Srinivasan et al., 1995). studied an airfoil oscillating for the assessment of turbulence models in unstable flows. It uses various turbulence models to operate on NACA0015 airfoil. Experimental findings have shown a good consistency with the lift, drag and moment coefficient spalart Allmaras turbulence model (Chervonenko et al., 1993) studied the effect of AOA on the non-stationary aerodynamic characteristics (Chuprun, 1993).

Investigated the deviation and validation of aerodynamics characteristics of NACA 0015 airfoil at different value of attack angle at different air velocities by determining the forces at every two degrees from 00 to 180 for experimental and numerical method (Rubel et al., 2016). While the authors used the low-speed wind tunnel in the experimental stage of the study, they used the ANSYS software in the numerical stage. At the end of the study, the authors claimed that both lift and drag coefficients rise as the attack angle is raised. The coefficient of drag gradually is dropped as the Reynolds number rises. However, the rise of Reynolds number coefficient of lift rises slightly and once at a certain point reduces (Rubel et al., 2016). Have examined the aerodynamic performance of a VAWT with Gurney flaps (Yan et al., 2020). The studies showed that the rotor's performance improves in the low tip-speed regime but degrades at higher rotational speeds. The Gurney flap heights used in these studies were limited to two values (Yan et al., 2020).

The primary purpose of this study is to investigate the aerodynamic behaviour of the new design (with a 5- 
degree flap) compared to the original design when a NACA 4415 type airfoil flap is added. Analyzes were performed under constant Reynolds numbers and an angle of attack between 0-10 degrees with a 1-degree interval.

\section{Methods}

\subsection{Theoretical Background}

Fluid viscosity is the most significant fluid element for low-speed airfoils. The viscosity produces lifting force indirectly, produces direct drag force and induces fluid separation. The Reynolds number expresses this influence. The ratio of inertial forces to viscous forces (internal friction) in any fluid is called the Reynolds number. The Reynolds number and its dependent parameters are shown as in Equation (1) (HF, 1979; Chen et al., 2017):

$$
\operatorname{Re}=\frac{\rho V_{0} l}{\mu}
$$

In Equation (1), $V_{0}$ is the average velocity of the flow, $L$ is the characteristic length of the flow, $\mu$ is the dynamic viscosity, and $\rho$ is the fluid density (Chen et al., 2017).

Airfoil architecture is an important element in aerodynamics. Various flight regimes show varying outputs. There are fundamental differences between symmetric and asymmetric airfoil like at zero-degree angle of attack; asymmetric airfoils can produce lift, whereas a frequently inverted flight suits symmetric airfoil as in the case of an aerobatic aircraft. Therefore, without boundary layer separation, we can use various angles. Subsonic airfoils have a round leading edge that is naturally insensitive to the angle of attack (Amano et al., 2009; Kanimozhi, 2018). The cross-section geometry of an example airfoil is shown in Fig. 1.

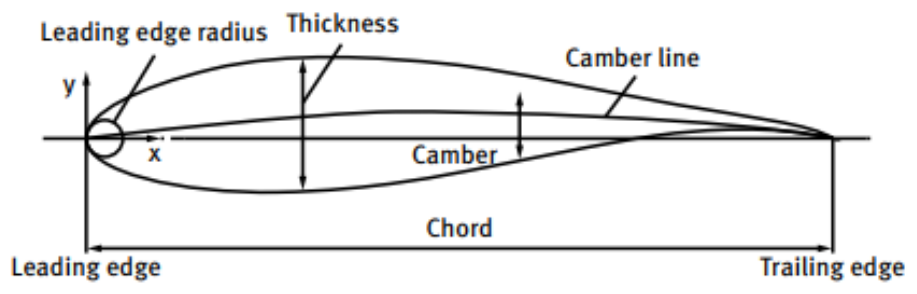

Fig. 1. The geometric parameters for an airfoil (Chen et al. 2017)

The leading edge is defined as the point on the front of the airfoil with maximum curvature. At the back of the airfoil, the trailing edge is known as a minimum point of curvature. The straight line joining the leading edge and trailing edge of the airfoil section is the chord line. The chamber line is the point locus between the top and the bottom of the airfoil. A different angle between free stream speed and chord lines is determined by taking the angle of attack. It is called the ratio ratio ratio of the span of an airfoil to the chord length of an airfoil (Kanimozhi, 2018). Mach Number is another important parameter in airfoil architecture. Equation (2) represents the relation of the Mach number to local velocity and speed of sound (Chen et al., 2017; Drela, 1982; Yi et al., 2005; Qian, 2005).

$$
M a=\frac{V}{V_{C}}
$$

The reacting force is generated by the wind interacting with the upper and lower airfoil. Two surface forces are obtainable; one is the normal force, that is to say, pressure; the other is the tangential force, that is, friction. Typically, the lift is the force component perpendicular to motion direction. Drag is called the component parallel to the movement direction. The pressure coefficient is defined as (Chen et al., 2017):

$$
C_{p}=\frac{p-p_{0}}{\frac{1}{2} \rho V_{0}^{2}}
$$

In Equation (3), $p_{0}$ is the pressure in the free flow, $p$ is the pressure to be obtained. When the flow hits the airfoil surface, there is a stagnation point at the leading edge. The stagnation point is defined as the point at which the fluid's local velocity is zero, and the pressure is at its maximum, i.e., the pressure coefficient $\mathrm{Cp}=+1.0$. Starting from the stagnation point, the flow over the stagnation line travels a short distance before bypassing the leading edge and proceeding along the upper surface to the trailing edge. At the leading edge, the flow will reach a high local velocity. The larger the AOA (Angle of Attack), the further back the stagnation point is and the higher the local velocity at the leading edge. The lowest pressure that corresponds to the peak speed could be highly negative. Meanwhile, the higher the AOA, the lower the pressure point is for the same airfoil (Chen et al., 2017).

Characteristics of a lifting airfoil usually mean the lifting coefficient curve vs AOA. The lift coefficient $\mathrm{Cl}$ is defined as (Chen et al., 2017):

$$
C_{l}=\frac{L}{\frac{1}{2} \rho V_{0}^{2} c}
$$

In Equation (4), $\mathrm{L}$ is the lift, $\rho$ is the density of the flow, $\mathrm{VO}$ is wind speed, and $\mathrm{c}$ is the length of the airfoil chord (Chen et al., 2017).

The Airfoil drag characteristics usually mean the curve of drag coefficient $\mathrm{Cd}$ variation vs AOA, but can also refer to the curve of drag coefficient vs lift coefficient (Chen et al., 2017).

$$
C_{d}=\frac{D}{\frac{1}{2} \rho V_{0}^{2} c}
$$


A plane force system is a theoretical mechanics synthesis of a force and torque at a given point. Pressure distribution on the surface of an airfoil can also be a synthesis of a force and a torque at a specific point. This torque is referred to as the pitching moment. In aerodynamic studies, this point is referred to as the acting point of force because the aerodynamic airfoil centre is incremental at the point of the lift, i.e., the torque at this point does not change with AOA. The pitching moment coefficient, like the lift and drag coefficients, is defined as follows (Chen et al., 2017):

$$
C_{m}=\frac{M}{\frac{1}{2} \rho V_{0}^{2} c^{2}}
$$

Pitching moment characteristics of an airfoil are typically defined as the curve of pitching moment coefficient $\mathrm{Cm}$ vs AOA. This curve varies linearly in the attached flow area, while the pitching moment coefficient remains constant around the aerodynamic centre (Chen et al., 2017).

\subsection{Airfoil Selection and Operating Parameters}

NACA 4415 type of airfoil was chosen for the analysis. The airfoil geometry is taken from Aerofoil Coordinates Database (UIUC, 2010). On the other hand, XFLR5 software was used for the software-based analysis. The software is open to public use and does not require any license (XFLR5, 2020; Yilmaz, 2018; Akdeniz, 2020). The analysis was performed depending on the following conditions.

\section{Operating Conditions:}

- Evaluations were performed via XFLR5 open code software.

- Discussed elements are the original design, NACA 4415, and flapped design, which added a 5-degree flap.

- Non-changeable Reynolds number which is 100,000 .

- Angles of attack range is 00 to 10 o degrees and 1degree intervals.

- Analyses were made at subsonic velocity value and considering 0.25 Mach number.

- Monitored parameters are aerodynamic coefficients of airfoil Cd, CL, and Cm for the original design and flapped design.

Beyond all of this, since the minimum stall velocity is an important parameter for the UAV characteristics, this parameter is also considered and compared for both cases. The minimum stall velocity is calculated according to Equation (7) (Selim, 2018; Akdeniz, 2020):

$$
V_{\text {stall }}=\sqrt{\left(\frac{2 W g}{\rho S C l_{\text {max }}}\right)}
$$

In Eq. (7), $\mathrm{W}$ is the total weight of the UAV to take-off, $\mathrm{S}$ is the wing surface area, and $\mathrm{C}_{\operatorname{lmax}}$ is the maximum lift coefficient. Thus, $\mathrm{C}_{\operatorname{lmax}}$ value indicates the maximum $\mathrm{C}_{\mathrm{L}}$ value that the wing profile can reach (Selim, 2018; Raymer, 2018; Akdeniz, 2020).

\section{Results}

The aerodynamic behaviour of the NACA 4415 type airfoil between 0 - and 10 - degrees angle of attack and a fixed 100,000 Reynolds number was obtained through the XFLR5 software. The results obtained first original design and then flapped design were combined. Once the conditions are determined, the lift and drag coefficients changes for the original design and flapped design in which both cases depending on the angle of attacks are given in Figure 2.

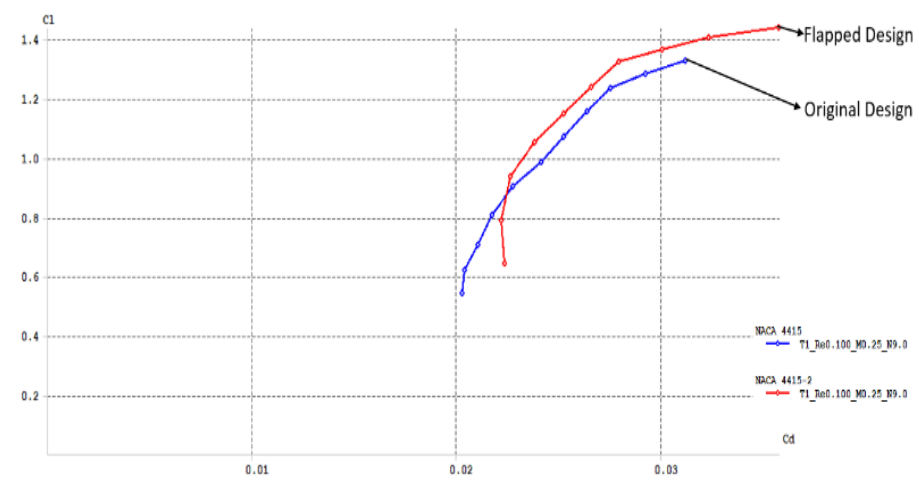

Fig. 2. $C_{L}-C_{D}$ variations due to angle of attack values

In Figure 2, the red line shows the design with a 5-degree flap added to the airfoil, while the blue line shows the original design. Figure 2 indicates that when the flap with 5 -degree is added to the airfoil, it has been observed that the Lift coefficient $\left(\mathrm{C}_{\mathrm{L}}\right)$ and Lift force of the wing increase significantly. In addition, the maximum coefficient of lift value was obtained when the angle of attack is 10 - degrees. The changes of the pressure coefficient for both cases depending on the angle of attack are given in Figure 3.

In Figure 3, the pressure coefficient of the Airfoil design with an added $5^{\circ}$ flap tends to decrease significantly compared to the original design. The changes of the $\mathrm{C}_{\mathrm{L}} / \mathrm{C}_{\mathrm{D}}$ for both cases depending on the angle of attack are given in Figure 4.

Figure 4 denotes that when the flap with $5^{\circ}$ is added to the airfoil, it has been observed that the drag coefficient $\left(C_{d}\right)$ of the wing increase partially.

According to Equation (7), $\mathrm{V}_{\text {stall }}$ results for both cases are obtained to be following: 


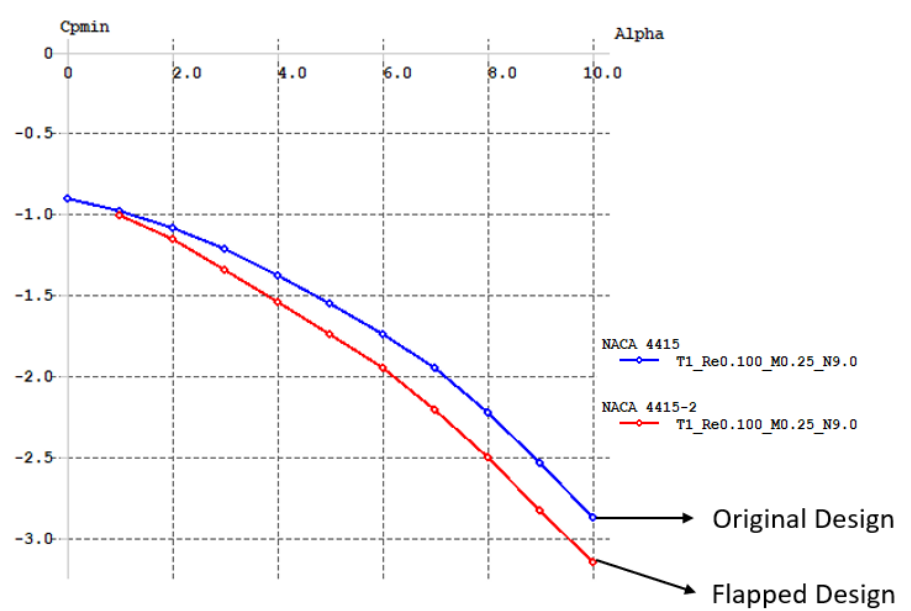

Fig.3. $\mathrm{C}_{\mathrm{pmin}}$ variations due to angle of attack values

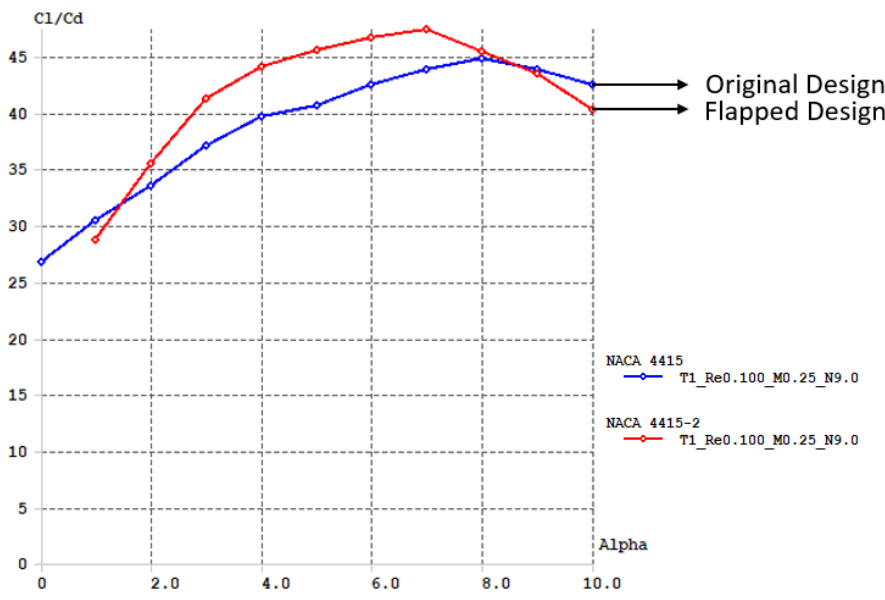

Fig. 4. $C_{L} / C_{D}$ variations due to angle of attack values

When the flap is added to the original design, the minimum stall velocity has decreased because wing weight and wing area increased. Additionally, $\mathrm{C}_{\mathrm{Lmax}}$ value increased. The maximum $\mathrm{C}_{\mathrm{Lmax}}$ value was obtained when the angle of attack was $10^{\circ}$.

\section{Conclusions}

This paper aims to analyze the aerodynamic behaviour of a NACA 4415 type airfoil at a fixed Reynolds number with a value of 100,000, angle of attack values between $0-10^{\circ}$, and when a $5^{\circ}$ flap is added to the airfoil design. Although the flapped design is named NACA 4415-2, some basic aerodynamic performance parameters have been observed using XFLR5 software. When the flap with 50 is added to the airfoil, it has been observed that the $\mathrm{C}_{\mathrm{L}}$ and Lift force of the original design of the airfoil increase significantly, $C_{D}$ of the airfoil increase partially. The pressure coefficient tends to decrease significantly. Furthermore, while the minimum stall velocity has decreased, $\mathrm{C}_{\mathrm{Lmax}}$ values increased.

\section{Nomenclature}

$\begin{array}{lll}\text { UAV } & : & \text { Unmanned Aerial Vehicle } \\ \mathrm{C}_{\mathrm{L}} & : & \text { Lift Coefficient } \\ \mathrm{C}_{\mathrm{D}} & : & \text { Drag Coefficient } \\ \mathrm{C}_{\mathrm{M}} & : & \text { Center of Gravity } \\ \mathrm{F}_{\mathrm{L}} & : & \text { Lift Force } \\ \mathrm{AOA} & : & \text { Angle of Attack } \\ \rho & : & \text { Density of Air } \\ \mathrm{V} & : & \text { Inlet Velocity of Air } \\ \mathrm{V}_{\text {stall }} & : & \text { Minimum Stall Velocity } \\ \mathrm{A} & : & \text { Area of the Airfoil } \\ \mathrm{F}_{\mathrm{D}} & : & \text { Drag Force } \\ \mathrm{R}_{\mathrm{e}} & : & \text { Reynolds Number } \\ \mu & : & \text { Dynamic Viscosity of the Fluid } \\ \mathrm{c} & : & \text { Chord Length }\end{array}$

\section{Acknowledment}

The author of this paper states that the presented work is an extended version of conference proceeding entitled "Performance Analysis Of A Wing Used In Unmanned Systems " which presented in ISEAS 2020.

\section{References}

Akdeniz, H.Y., 2020, Performance Analysis of a Wing Used in Unmanned Systems, International Symposium on Electric Aviation and Autonomous Systems - International Symposium on Aircraft Technology, MRO and Operations Proceedings, 2020: Kyiv, Ukraine.

Alam, G.J. and Mamun, M., 2021, February. Aerodynamic Characteristics of Aerofoil Shaped Fuselage UAV Model and Compare With the Conventional Model Using CFD Software. In AIP Conference Proceedings (Vol. 2324, No. 1, p. 040001). AIP Publishing LLC.

Arunvinthan, S. and Pillai, S.N., 2019, Aerodynamic characteristics of unsymmetrical aerofoil at various turbulence intensities. Chinese Journal of Aeronautics, 32(11), pp.2395-2407.

Chen, J., Wang, Q. and Sun, Z. eds., 2017, Wind turbine airfoils and blades: Optimization design theory. China Science Publishing \& Media Lt, De Gruyter.

Chervonenko, A.G., Kaminer, A.A., Berne, A.L. and Chuprun, O.B., 1993, effect of attack angle on the non-stationary aerodynamic characteristics and flutter resistance of a grid of bent vibrating compressor blades. Strength of materials, 25(10), pp.768-771.

Drela, M., 1986, Two-dimensional transonic aerodynamic design and analysis using the Euler equations. Cambridge, Mass.: Gas Turbine Laboratory, Massachusetts Institute of Technology.

FAS, 2021a, Next Generation Air Transportation System Unmanned Aircraft Systems Research, 
Development and Demonstration Roadmap, available at: https://fas.org/irp/program/collect/uasnextgen.pdf (accessed 16 May 2021)

FAS, 2021b, Unmanned Aircraft Systems Roadmap 2005 - 2030, https://fas.org/irp/program/collect/uav_roadm ap2005.pdf Access Date: 16.05.2021

Gupta, S.G., Ghonge, M.M. and Jawandhiya, P.M., 2013, Review of unmanned aircraft system (UAS). International journal of advanced research in computer engineering \& technology (IJARCET), 2(4), pp.1646-1658.

Phillips, H.F., 2004, Flying Wings - Aviation and Aeromodelling - Interdependent Evolutions and Histories,

Http://Www.Ctie.Monash.Edu.Au/Hargrave/Phill ips.Html. HF,

$\mathrm{Xu}$, 1979, Fundamentals of Aerodynamics. Peking: National Defense of Industry Press

Joseph Daniel, S., 2020, Performance Analysis of Asymmetrical airfoil for Subsonic flight using XFLR5 software, The International Journal of Progressive Research in Science and Engineering, 1(8), pp.8-11.

Kadvea, A., Sharmab, P., Patelc, A., 2016, Review on CFD analysis on aerodynamic design optimization of wind turbine rotor blade, International Journal of Innovative and Emerging Research in Engineering, 3(5), pp.178-182.

Kanimozhi, G. V., 2018, Analysis of Airfoil Flow Pattern using CFD., in: International Journal of Engineering Research \& Technology (IJERT) Confcall - 2018 Conference Proceedings. ISSN: 2278-0181 Published by, www.ijert.org

Nonami, K., Kendoul, F., Suzuki, S., Wang, W. and Nakazawa, D., 2010, Autonomous flying robots: unmanned aerial vehicles and micro aerial vehicles. Springer Science \& Business Media.

Qian, YJ., 2005, Aerodynamics. Beijing University of Aeronautics and Astronautics Press, Peking.

Quintana, E., 2008, The ethics and legal implications of military unmanned vehicles. RUSI, Occasional Paper.

Raymer, D., 2018, Aircraft Design: A Conceptual Approach, Sixth Edition. American Institute of Aeronautics and Astronautics, Inc., Washington, DC

Rubel, R.I., Uddin, M.K., Islam, M.Z. and Rokunuzzaman, M.D., 2016, Numerical and experimental investigation of aerodynamics characteristics of NACA 0015 aerofoil. International Journal of Engineering Technologies, 2(4), pp.132-141.

Khan, S., Ilkal, S. H., Rekha, R., 2019, Design of High Lift Low Reynolds Number Airfoil for Micro Aerial
Vehicle, International Journal of Innovative Science and Research Technology, 4(3), pp.186-192.

Selïm, S., Akşar, E., 2018, Sabit Kanatli İnsansiz Hava Araçlarinda (IHA) Kanat Tasariminin Uçuş Süresi, Manevra Kabiliyeti ve Kalkiş Hizi (vstall) Üzerine Etkilerinin Araştirilmasi, in Uzaktan algilama ve cbs sempozyumu uzal-cbs 2018: Eskişehir Teknik Üniversitesi.

Srinivasan, G.R., Ekaterinaris, J.A. and McCroskey, W.J., 1995, Evaluation of turbulence models for unsteady flows of an oscillating airfoil. Computers \& Fluids, 24(7), pp.833-861.

UIUC Aerofoil Coordinates Database, 2010, available at: https://mselig.ae.illinois.edu/ads/coord_databas e.html (accessed 2020)

Vogeltanz, T., 2016, A survey of free software for the design, analysis, modelling, and simulation of an unmanned aerial vehicle. Archives of Computational Methods in Engineering, 23(3), pp.449-514.

XFLR5, 2020, available at: http://www.xflr5.com/xflr5.html (accessed 29 July 2020)

Yan, Y., Avital, E., Williams, J. and Cui, J., 2020 , Performance improvements for a vertical axis wind turbine by means of Gurney flap. Journal of Fluids Engineering, 142(2).

Yi, Z., Wu, X. and Zhou, LZ., 2005, Low Speed Aerodynamics. Press of Metallurgy Industry, Peking.

Yiğit, E., Yazar, I. and Karakoç, H.T., 2018, İnsansız Hava Araçları (IHA)'nın Kapsamlı Sinıflandırması ve Gelecek Perspektifi. Sürdürülebilir Havacılık Araştırmaları Dergisi, 3(1), pp.10-19.

Yilmaz, I. 2018, available at: https://uavturkey.tubitak.gov.tr/assets/2018_iha _egitim_ilker_yilmaz.pdf (accessed 17 April 2020) 